\title{
BMJ Open How do women with chronic fatigue syndrome/myalgic encephalomyelitis rate quality and coordination of healthcare services? A cross-sectional study
}

\author{
Anne Helen Hansen, ${ }^{1}$ Olaug S Lian ${ }^{2}$
}

To cite: Hansen AH, Lian OS. How do women with chronic fatigue syndrome/myalgic encephalomyelitis rate quality and coordination of healthcare services? A crosssectional study. BMJ Open 2016;6: 010277. doi:10.1136/bmjopen-2015010277

- Prepublication history for this paper is available online. To view these files please visit the journal online (http://dx.doi.org/10.1136/ bmjopen-2015-010277).

Received 20 October 2015 Revised 12 January 2016 Accepted 18 January 2016

CrossMark

\section{${ }^{1}$ Faculty of Health Sciences, Department of Community Medicine, UiT The Arctic University of Norway and Norwegian Centre for Integrated Care and Telemedicine, University Hospital of North Norway, Tromsø, Norway \\ ${ }^{2}$ Faculty of Health Sciences, Department of Community Medicine, UiT The Arctic University of Norway, Tromsø, Norway}

Correspondence to Dr Anne Helen Hansen; anne.helen.hanzen@gmail. com

\section{ABSTRACT}

Objective: To test the association between self-rated health and self-rated degree of chronic fatigue syndrome/myalgic encephalomyelitis (CFS/ME), and CFS/ME patients' assessment of quality of primary care, specialist care and coordination of care.

Design: Cross-sectional study.

Setting: Self-reported questionnaire data from women members of The Norwegian ME Association obtained in 2013.

Participants: 431 women with CFS/ME aged 16-73 years.

Main outcome measure: The participants' assessment of quality in primary care, specialist care and in coordination of care (good/very good or poor/ very poor). Main explanatory variables: self-rated health and self-rated degree of CFS/ME.

Results: Quality of care was rated poor by $60.6 \%$ in primary care, by $47.7 \%$ in specialist care, and by $71.2 \%$ regarding coordination of care. Poorer self-rated health increased the probability of rating quality in primary care poor, particularly among women 40 years and over (OR 2.38, 95\% $\mathrm{Cl} 1.63$ to 3.49), women with university education (OR 2.57, Cl 1.68 to 3.94 ), and owing to less frequent general practitioner (GP) visits (OR 2.46, $\mathrm{Cl} 1.60$ to 3.78). Poorer self-rated health increased the probability of rating quality poor in specialist care (OR 1.38, $\mathrm{Cl} 1.05$ to 1.82 ), but not in coordination of care. A more severe CFS/ME was associated with a higher probability of rating quality in primary care poor (OR $0.61, \mathrm{Cl} 0.38$ to 0.93 ). Frequent visitors and those with a long GP relationship were less likely to report primary care quality as poor.

Conclusions: A large proportion of women with CFS/ ME rated quality of care poor/very poor in primary care, specialist care and in coordination of care. The dissatisfaction was higher for primary care than for specialist care. Overall, poorer self-rated health and a more severe CFS/ME were associated with lower quality scores in primary and specialist care, but not in coordination of care. Healthcare services, as assessed by women with CFS/ME, do have a large potential for improvement.

\section{Strengths and limitations of this study}

- Recruitment of a homogeneous group of study participants from a patient organisation is a study strength.

- The use of a systematically tested questionnaire and an acceptable response rate are strengths.

- There might be a selection bias due to recruitment from a patient organisation, and a possible recall bias as for most questionnaire data, which are limitations of the study.

- The validity of self-reported measures might be discussed, and in particular measures of disease severity and health.

- The cross-sectional design precludes any causal interpretation.

\section{INTRODUCTION}

Chronic fatigue syndrome/myalgic encephalomyelitis (CFS/ME) is a condition with an estimated prevalence around 1-2 per thousand. ${ }^{1}$ It affects women more than men $(70$ $85 \%$ ) and its aetiology is unknown. ${ }^{2-4}$ CFS/ $\mathrm{ME}$ is characterised by its fluctuating nature, physical and mental fatigue, persistent postexertional malaise, sleep disturbances, problems with concentration and memory, pain in muscles and joints, headache, and other symptoms related to cognitive, immune and autonomous dysfunctions. ${ }^{5-7}$ The terms CFS and $\mathrm{ME}$ are used interchangeably but mostly as a composite term, and the distinction between them is disputed..$^{5}$ In this paper, we use the combined term CFS/ME as recommended by Norwegian health authorities and others. ${ }^{78}$

CFS/ME cannot be confirmed by specific tests, it is not localised to a specific part of the body, and it challenges the traditional distinction between psyche and soma. ${ }^{9}$ In line with this, CFS/ME is a controversial 
condition and poses particular challenges in terms of diagnosis, therapy and communication, both to patients as well as to physicians. ${ }^{10}$

Patients with CFS/ME often need coordinated health services from multiple providers over time. General practitioners (GPs) are their main contacts. All Norwegian citizens are provided a regular GP, and only $0.4 \%$ of the population has chosen to remain outside GPs' lists. ${ }^{11}$ Residents can change GPs twice a year without justification. Together with universal tax-funding and gatekeeping, the list system provides strong incentives for personal continuity of care. ${ }^{12}$ First-line medical services including emergency clinics are run by the municipalities. Specialist services, consisting of hospitals and outpatient clinics, are run by regional health enterprises and are mainly owned by the state. Access is usually achieved by referrals from the GP (the gatekeeper role). GP and specialist outpatient visits are co-paid by adult patients.

Healthcare services, and GPs in particular, are well regarded in the population. ${ }^{13}$ However, Norway's scores in the annual patient/population assessed international comparisons of health systems by the Commonwealth Fund (CWF) have been less than average in areas like general quality of care, waiting time for appointments, information sharing, communication and coordination of services. ${ }^{14}{ }^{15}$ Patient satisfaction, defined as 'an individual's cognitive evaluation of, and emotional reaction to, his or her health-care experience, ${ }^{16}$ is considered an important indication of overall quality in healthcare. ${ }^{17}$ The Norwegian scores thereby indicate particular challenge areas for healthcare providers and policymakers.

Across healthcare settings, patient satisfaction or patients' assessment of healthcare quality is positively associated with better self-rated health and functional status and inversely associated with the complexity of health problems. ${ }^{18-21}$ In striving towards evidence-based improvement of healthcare delivery, research on patientbased assessments of quality and coordination is informative, especially for groups with chronic diseases and long-term needs of care from multiple providers, like CFS/ME. Moreover, this group of patients is interesting due to previously reported serious challenges in collaboration with healthcare services and providers, in line with the contested status of the condition. ${ }^{9}$

The familiar measure self-rated health captures a comprehensive range of aspects and provides summative information about the individual's history of health and disease as well as the current level of health. ${ }^{22} 23$ However, a measure related to the disease of interest might provide a more specific indication of how disease severity and patients' ratings might be associated. Self-rated degree of CFS/ME might be such a measure. Solid evidence whether differences in health status might be associated with CFS/ME patients' assessment of quality has been lacking.

We embarked on this study for three main reasons. First, there is a need to explore how a challenging condition like CFS/ME relates to patients' evaluations. Second, we wanted to explore possible associations between quality assessment and health status as measured both by self-rated health and by a more specific measure related to CFS/ME. Third, we wanted to investigate CFS/ME patients' evaluation of primary and specialist care as separate entities, as well as their evaluation of coordination between caregivers.

In the present study, we had the opportunity to explore all of these aspects, which is relevant because it may influence GPs', specialists', patients' and policymakers' awareness of assessed quality, with possible consequences for clinical practice, communication, cooperation, health outcomes and planning and organising of health services for patients with CFS/ME.

Our aim was to study how patients with CFS/ME rated healthcare quality and coordination of services, and to investigate whether self-rated health and self-rated degree of CFS/ME were associated with CFS/ME patients' assessment of quality in primary and specialist care, and in the coordination of care.

\section{METHODS \\ Data}

This cross-sectional study used postal survey data obtained in April and May 2013 from members of The Norwegian ME Association. Invitations were distributed by the Norwegian Social Science Data Service (NSD) Web Survey to a total of 811 members with known email addresses (about $40 \%$ of all members). Non-respondents were given one reminder.

Initially, we had no information about age or reasons for membership; thus, members were asked to refrain from participating if they were below 16 years or if they did not suffer from CFS/ME themselves (health professionals, parents, others). We do not know how many of the non-respondents were not eligible to participate, and therefore an exact response rate cannot be calculated. Other parts of this study have been published previously. ${ }^{24}$

The questionnaire included information about demographic and socioeconomic characteristics, health status including specific questions about symptoms, duration, severity and treatment of their CFS/ME, and use of and experiences with healthcare services. The questions used in this study were based on a questionnaire previously validated and used in an evaluation of GP services in Norway, ${ }^{25}$ and the revised version was piloted among 143 people belonging to the targeted groups before the final design was settled on.

\section{Participants}

Women comprised $89.1 \%$ of the 488 respondents. Owing to low numbers, as well as to avoid overfitting ${ }^{26}$ and a possible confounding effect of gender in the regression models, we excluded all men (53 respondents). We also excluded those who did not give 
information about gender (2 respondents) or age (2 respondents). This gave a net sample of 431 respondents (figure 1).

\section{Variables}

Participants were asked about their overall personal experiences with quality and coordination of follow-up and treatment in healthcare services, from their first contact because of CFS/ME and until the time of the survey. The dependent variables were based on the three questions presented in table 1 . For an easier interpretation of logistic regressions, all three variables were dichotomised by merging the original answering options into 'good/very good' and 'poor/very poor'. Those who answered 'not relevant' were excluded from the analyses.

The key independent variables were self-rated health and self-rated degree of CFS/ME. Self-rated health was obtained from the question 'How would you assess your own health in general?' Response options were reduced from five original categories (very poor-poor-fairgood-excellent) to four by merging the good and excellent categories due to low numbers (five individuals reported excellent health). Self-rated degree of CFS/ME was obtained from the question 'What degree of ME do you have as of today?' Four answering options were given: mild (about $50 \%$ reduction in activity), moderate (housebound most of the day), severe (bedridden most of the day) and very severe (completely bedridden). This classification, defined by an international consensus panel, ${ }^{27}$ has been widely discussed in the ME Association's membership magazine, and is well known to the members of the ME Association. We merged the severe and very severe categories due to low numbers (five individuals reported very severe disease).

Adjustment independent variables were age, education, duration of the current GP relation (GP duration), and number of GP visits during the previous year (GP frequency). Six original education categories were merged into four due to low numbers in the outermost groups (one individual with no education and three individuals with a $\mathrm{PhD}$ ). GP duration was obtained from the question 'Approximately for how long have you had your current GP?' Responses were dichotomised into 02 years and 3 years or more. GP frequency was obtained from the question 'Approximately how many times have you seen your GP, another GP or visited an emergency clinic during the previous 12 months for issues related to your ME?' The answers were categorised into four levels: 0 visits, $1-4$ visits, $5-9$ visits, and 10 visits or more.

\section{Analyses}

Data were analysed by means of descriptive statistics and logistic regressions. Correlations were tested with Spearman's correlation coefficients.

We constructed two sets of multivariable regression models for each of the three dependent variables. The first set included the independent variables self-rated health, age, education, GP duration and GP frequency, which were introduced collectively into the model. In the second set of models, self-rated health was replaced by self-rated degree of CFS/ME. We performed dummy analyses as well as trend analyses. Since some of the groups were small, and there was no significant lack of linearity, we chose to report the trend analyses exclusively. We tested first-order interactions by introducing interaction terms in the regression models. Where interactions were present, we performed stratified analyses accordingly.

We used 95\% CIs throughout the study. All analyses were accomplished using Stata, V.13.1.

\section{RESULTS}

In total, 488 members of the ME association aged 1673 years (mean age 46.2 years) participated, constituting
Figure 1 Flow chart of study participants. CFS/ME, chronic fatigue syndrome/myalgic encephalomyelitis.

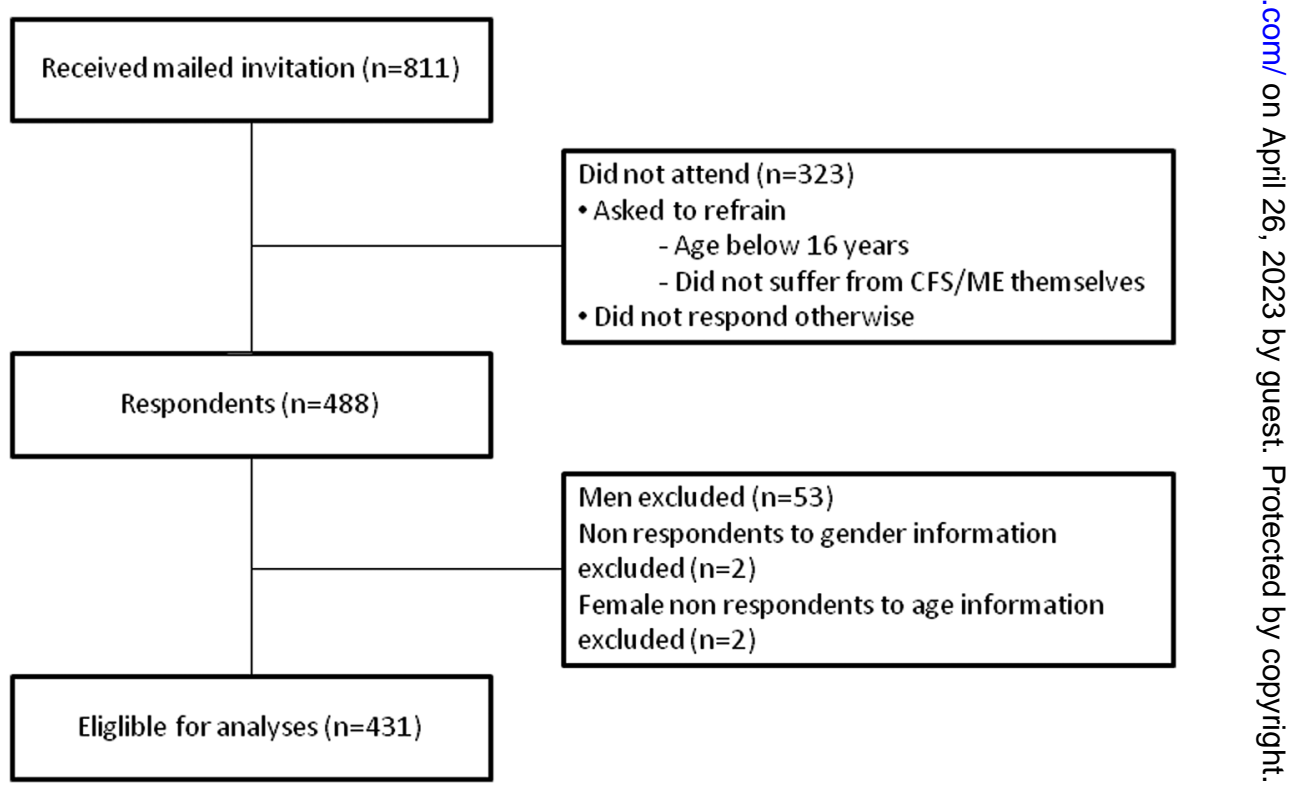


Table 1 Female CFS/ME patients' assessment of quality in primary care, specialist care and in coordination of care (\%)

\begin{tabular}{llllll}
\hline & $\begin{array}{l}\text { Very good } \\
\mathbf{n}(\%)\end{array}$ & $\begin{array}{l}\text { Good } \\
\mathbf{n}(\%)\end{array}$ & $\begin{array}{l}\text { Poor } \\
\mathbf{n}(\%)\end{array}$ & $\begin{array}{l}\text { Very poor } \\
\mathbf{n}(\%)\end{array}$ & $\begin{array}{l}\text { Not relevant } \\
\mathbf{n}(\%)\end{array}$ \\
\hline $\begin{array}{l}\text { How would you describe the quality of the medical } \\
\text { care you have received from primary care? }(\mathrm{n}=396)\end{array}$ & $30(7.6)$ & $114(28.8)$ & $132(33.3)$ & $108(27.3)$ & $12(3.0)$ \\
$\begin{array}{l}\text { How would you describe the quality of the medical } \\
\text { care you have received from specialist care? (n=392) }\end{array}$ & $33(8.4)$ & $128(32.7)$ & $106(27.0)$ & $81(20.7)$ & $44(11.2)$ \\
$\begin{array}{l}\text { How do you think the services in the various parts of } \\
\text { the support system are coordinated? (n=385) }\end{array}$ & $2(0.5)$ & $61(15.8)$ & $152(39.5)$ & $122(31.7)$ & $48(12.5)$ \\
\hline \begin{tabular}{l} 
CFS/ME, chronic fatigue syndrome/myalgic encephalomyelitis. \\
\hline
\end{tabular}
\end{tabular}

an overall estimated response rate of $60 \%$ (figure 1 ). Owing to the non-response from non-eligible receivers and return of emails from email addresses that were not in use, the actual response rate is assumed to be higher. The 431 women constituting the final sample for analyses reported having the diagnoses ME $(n=354)$, CFS $(\mathrm{n}=31)$ and/or post viral fatigue syndrome $(\mathrm{n}=70)$ (more than one diagnosis possible).

Most participants (61.8\%) had suffered from CFS/ME for 10 years or more. The highest percentage of people were aged 40-59 years, had university education, poor self-rated health, moderate degree of CFS/ME, a GP relation of 3 years or more and 1-4 GP visits during the previous year (table 2). In the previous year, $92 \%$ of the patients had visited primary healthcare services at least once for issues related to their CFS/ME (table 2).

The quality of medical care was assessed as poor/very poor by $60.6 \%$ in primary care, and by $47.7 \%$ in specialist care, whereas $71.2 \%$ of the participants regarded coordination between services as poor/very poor (table 1).

In multivariable analyses, we found that the associations between primary care quality assessments and selfrated health were modified by age (interaction term between self-rated health and age, $p$ value $(p)=0.010)$, education (interaction term between self-rated health and education, $\mathrm{p}=0.016$ ) and GP frequency (interaction term between GP frequency and self-rated health, $\mathrm{p}=0.025$ ), indicating a stronger association between poorer quality assessment and poorer self-rated health among women in higher age, with higher education and owing to less frequent GP visits. In analyses stratified by age, education and GP frequency, these associations were statistically significant only in women 40 years and over, in women with university education and in women who visited their GP four times or less during the previous year (table 3 ).

Poorer self-rated health increased the probability of reporting the quality as poor/very poor in specialist care, whereas we made no significant findings regarding coordination of care (table 4).

In models where self-rated health was replaced by selfrated degree of $\mathrm{CFS} / \mathrm{ME}$, we found that a more severe CFS/ME increased the probability of rating quality in primary care poor/very poor (table 5). In this model, those who had the same GP for 3 years or more, and those who visited more frequently, were less likely to report the quality of primary care as poor/very poor. The effect modifications in the self-rated health model were not replicated in this model. No significant associations in quality reports were observed for specialist care or coordination of care (table 5).

There were no strong correlations (defined as rho $>0.5$ ) between any of the independent variables in any of the models. We found a modest correlation between selfrated health and self-rated degree of CFS/ME $($ rho $=0.5067)$, but both these variables were not included in any model.

\section{Table 2 Sample characteristics}

\begin{tabular}{|c|c|c|}
\hline & \multicolumn{2}{|c|}{ Total sample } \\
\hline & $\mathbf{n}$ & Per cent \\
\hline Age, years & 431 & 100.0 \\
\hline $16-19$ & 5 & 1.2 \\
\hline 20-39 & 116 & 26.9 \\
\hline $40-59$ & 244 & 56.6 \\
\hline $60+$ & 66 & 15.3 \\
\hline Education & 398 & 100.0 \\
\hline Primary & 29 & 7.3 \\
\hline High school & 128 & 32.1 \\
\hline University $1-4$ years & 156 & 39.2 \\
\hline University 5 years+ & 85 & 21.4 \\
\hline Self-rated health & 399 & 100.0 \\
\hline Very good/excellent & 44 & 11.0 \\
\hline Fair & 83 & 20.8 \\
\hline Poor & 205 & 51.4 \\
\hline Very poor & 67 & 16.8 \\
\hline Degree of CFS/ME & 396 & 100.0 \\
\hline Mild & 88 & 22.2 \\
\hline Moderate & 268 & 67.7 \\
\hline Severe/very severe & 40 & 10.1 \\
\hline GP duration & 398 & 100.0 \\
\hline $0-2$ years & 144 & 36.2 \\
\hline 3 years+ & 254 & 63.8 \\
\hline GP frequency* & 368 & 100.0 \\
\hline 0 visits & 29 & 7.9 \\
\hline $1-4$ visits & 159 & 43.2 \\
\hline $5-9$ visits & 107 & 29.1 \\
\hline $10+$ visits & 73 & 19.8 \\
\hline
\end{tabular}




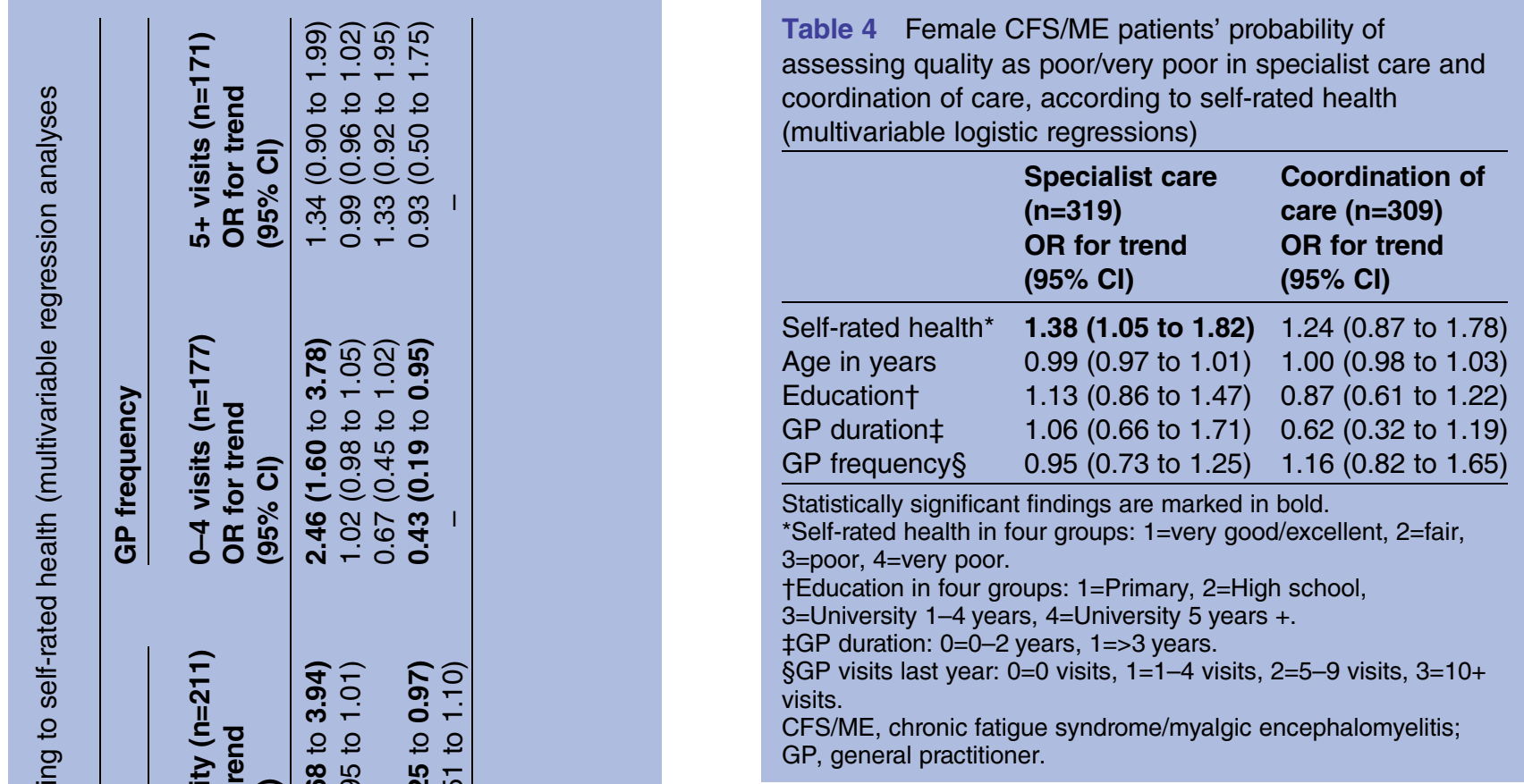

Table 4 Female CFS/ME patients' probability of coordination of care, according to self-rated health (multivariable logistic regressions) GP, general practitioner

\section{DISCUSSION}

We found that primary and specialist care quality was rated as poor/very poor by 60.6 and $47.7 \%$ of study participants, respectively. Poorer self-rated health increased the probability of poor/very poor quality scores both in primary and specialist care. In primary care, these findings were statistically significant among women 40 years and over, among women with higher education, and among women who visited their GP four times or less during the previous year. A more severe CFS/ME was associated with a higher probability of rating primary care, but not specialist care, poor. Coordination of care was assessed poor/very poor by most of the study participants, regardless of self-rated health and self-rated degree of CFS/ME. Overall, frequent visitors and those with a long GP relationship were less likely to report poor primary care quality.

CFS/ME patients' assessment of healthcare services in relation to self-rated degree of CFS/ME is largely unknown, as this measure has hardly been used in previous studies. Self-rated health is a more commonly used but less specific measure as it refers to general health and not specifically CFS/ME-related health. Our finding that poorer self-rated health was associated with lower quality scores confirms those of most previous studies across diagnoses and healthcare settings. ${ }^{18-21} 28$ It is worth noting that similar findings were slightly weaker for self-rated degree of CFS/ME compared to self-rated health, indicating that self-rated health encompasses a wider range of issues and complexity of health problems, ${ }^{1922} 23$ even for patients with a complex and challenging condition like CFS/ME. This is also confirmed by a no more than modest correlation between these two variables. 
Table 5 Female CFS/ME patients' probability of assessing quality as poor/very poor in primary care, specialist care and coordination of care, according to self-rated degree of CFS/ME (multivariable logistic regressions)

\begin{tabular}{|c|c|c|c|}
\hline & $\begin{array}{l}\text { Primary care }(n=346) \\
\text { OR for trend }(95 \% \mathrm{Cl})\end{array}$ & $\begin{array}{l}\text { Specialist care }(n=317) \\
\text { OR for trend } 95 \% \mathrm{CI}\end{array}$ & $\begin{array}{l}\text { Coordination of care }(n=308) \\
\text { OR for trend } 95 \% \mathrm{Cl}\end{array}$ \\
\hline Degree of CFS/ME* & 1.68 (1.10 to 2.57$)$ & 1.46 (0.95 to 2.24$)$ & $1.52(0.87$ to 2.67$)$ \\
\hline Age in years & 1.00 (0.98 to 1.02$)$ & 0.98 (0.96 to 1.01$)$ & 1.01 (0.98 to 1.03$)$ \\
\hline Education† & $1.05(0.81$ to 1.37$)$ & $1.18(0.90$ to 1.54$)$ & 0.86 (0.61 to 1.22$)$ \\
\hline GP duration $\ddagger$ & 0.61 (0.38 to 0.99$)$ & $1.00(0.62$ to 1.60$)$ & 0.61 (0.32 to 1.17$)$ \\
\hline GP frequency§ & 0.70 (0.54 to 0.93$)$ & $0.94(0.72$ to 1.24$)$ & $1.14(0.80$ to 1.64$)$ \\
\hline \multicolumn{4}{|c|}{$\begin{array}{l}\text { Statistically significant findings are marked in bold. } \\
\text { *Degree of ME in } 3 \text { groups: } 1=\text { mild, } 2=\text { moderate, } 3=\text { severe/very severe. } \\
\text { †Education in four groups: } 1=\text { Primary, } 2=\text { High school, } 3=\text { University } 1-4 \text { years, } 4=\text { University } 5 \text { years }+ \text {. } \\
\text { †GP duration: } 0=0-2 \text { years, } 1=>3 \text { years. } \\
\text { §GP visits last year: } 0=0 \text { visits, } 1=1-4 \text { visits, } 2=5-9 \text { visits, } 3=10+\text { visits. } \\
\text { CFS/ME, chronic fatigue syndrome/myalgic encephalomyelitis; GP, general practitioner. }\end{array}$} \\
\hline
\end{tabular}

Overall, quality in primary care was more likely reported low by patients with a shorter GP relation and less frequent GP visits. These variables might be intertwined. Previous studies have suggested that continuity of GP care is associated with higher patient satisfaction, ${ }^{24}$ and that people in poorer health are more likely to have shorter GP relationships. ${ }^{12}$ Some of these patients might suffer from ailments that do not fit into specific diagnoses, thus generating dissatisfaction and a search for another GP. ${ }^{28}$ In this study, $36.2 \%$ reported a short duration of their GP relation, indicating that patients with CFS/ME might replace their GPs to a higher extent than the general population. ${ }^{12}$ In line with our findings, others have reported a positive GP assessment to be associated with increased frequency of attendance. ${ }^{28}$ This might indicate that once patients have found an understanding GP, they consider GP visits beneficial and therefore visit more frequently.

In an international comparison of patient-evaluated GP care in 10 European countries, $76 \%$ of Norwegian patients viewed care as good/excellent, a score below the study average. ${ }^{29}$ Only $36.4 \%$ of our study participants viewed GP care as good/very good. Despite differences between the studies, both strongly indicate that patients with CFS/ME are less satisfied than the general population. This is reinforced by the fact that there are only women in our study, as women in general are more satisfied with healthcare than men. ${ }^{30}$ Regarding the notion that communication and the GP-patient relationship are important tools in the treatment of medically contested conditions like CFS/ME, ${ }^{31}$ this is a cause for concern.

Slightly more than half of the participants reported the quality of specialist care as good/very good. A Swedish study of outpatient care in all hospital specialties found that on average more than $80 \%$ were satisfied, ${ }^{30}$ which largely contradicts our findings. Hence, similar to primary care, patients with CFS/ME seem to be less satisfied than patients in general. This is not surprising, since quality of healthcare is often regarded lower by people in poorer health. ${ }^{18} 1921$
We found that quality scores for specialist care were better than for primary care. Previous research reports that many GPs are constrained by the scientific uncertainty of $\mathrm{CFS} / \mathrm{ME},{ }^{32}$ unconfident with diagnosing and treating the condition, ${ }^{33}$ and worried that the label of CFS/ME might be potentially harmful to the patient. ${ }^{34}$ Patients with CFS/ME or other medically unexplained conditions, on the other hand, have reported feeling belittled, stigmatised, distrusted, rejected and ignored by their doctors, and that their moral character and the reality of their symptoms are questioned. ${ }^{35} 36$ These aspects might partly explain the low quality scores, especially in primary care where doctors are likely to be more sceptical towards the CFS/ME diagnosis than those who have specialised in dealing with them. ${ }^{37} \mathrm{We}$ reported in a previous paper that patients do value referrals ${ }^{24}$ which is in accordance with patients' reports that specialist services provide acknowledgement of their ailments, treatment, better handling of daily life issues and improved dialogue between professionals. ${ }^{38}$ However, patients with CFS/ME often have to struggle for a referral, ${ }^{39}{ }^{40}$ which might affect the relationship with their GP. Patients in Europe have evaluated GP care more positively in countries without gatekeeping, ${ }^{29}$ and the Norwegian gatekeeping system could explain some of the low primary healthcare scores.

Quality in coordination of care was rated as poor/very poor by $71.2 \%$ of the patients, with no significant differences according to the independent variables in the study. This corresponds to experiences of patients with complex healthcare needs internationally ${ }^{41}$ and with the Norwegian scores in the CWF international comparisons. ${ }^{14}{ }^{15}$ Despite the Norwegian Coordination Reform (2012) aiming to facilitate better coordination in healthcare, ${ }^{42}$ challenges seem large in this field.

Are self-rated health and self-rated degree of CFS/ME to be regarded as measures of individual characteristics or measures of health outcome? This is worth some reflection considering the controversies of this condition, where communication between patient and doctor is regarded as an important treatment tool. ${ }^{31}$ Most 
participants in our study reported poor health and a moderate to severe degree of CFS/ME, thus indicating a complex health situation. The individual characteristic perspective may indicate that poor quality of care is influenced by the patients' receptiveness of the offered care, which in turn may lead to blaming the patient herself for a possible poor quality. On the other hand, the outcome perspective might indicate that poor quality of care is influenced by the healthcare providers' inability to handle patients and their condition, which in turn may lead to blaming the doctor and healthcare services for a possible poor quality. In real life, these perspectives might be intertwined. However, according to professional ethics and healthcare laws, ${ }^{43}$ the doctor is the one responsible for quality in the medical encounter, regardless of the patient characteristics and issues raised. Considering health status as (at least partly) a measure of outcome, it is not surprising that poorer selfrated health and a more severe degree of CFS/ME was associated with lower quality scores. In line with this, we assume that patients emphasise the outcome perspective. This notion might also be underpinned by the result that the low quality scores for primary and specialist services both were associated with poorer health status, whereas coordination of care was not.

A particular strength of the study was the recruitment of study participants from a patient organisation since it is detached from sites of care, with the aim of enabling patients to describe their experiences without fear of how this information might affect their relation to healthcare providers. We used a well-designed, systematically tested questionnaire, and the response rate was acceptable. By studying a specific group of patients, we have been able to interpret our findings according to a relatively homogeneous group.

This study had some limitations. Our sample may not fully represent women with CFS/ME. First, there might be a selection regarding membership of the patient organisation. Survivor bias may be a part of this, indicating that the healthiest patients will not demand membership to the same extent as those in poorer health. ${ }^{44}$ On the other hand, the most seriously affected members might have refrained from participating because of disease severity. The direction of a possible selection bias from these factors is not obvious. A general population satisfaction study reported that non-respondents were over-represented in groups with lower satisfaction, ${ }^{30}$ indicating that a possible selection bias might have skewed our study in the direction of better satisfaction scores than would otherwise be found. However, female patients with CFS/ME might differ from this population. ${ }^{36}$ Second, the distribution of email addresses might have been skewed, for instance towards younger members with higher education. However, since $93 \%$ of Norwegian households have access to the internet, ${ }^{45}$ we find it unlikely that this have influenced our results to a significant degree. Third, our sample had lower age and higher education than the Norwegian average. $^{46}$ A possible skewness regarding these variables might be connected, since younger individuals will not have completed their education.

In questionnaire data, there is always a potential for recall bias, particularly regarding minor events and the distant past, usually leading to under-reporting. Some studies indicate that doctors hold the opinion that patients with CFS/ME often exaggerate the severity of their ailments, ${ }^{36}$ and it is difficult to judge whether over-reporting or under-reporting might be present in our data. The validity of self-reported data on disease severity may be disputable per se, but in the case of CFS/ME, where no objective tests are diagnostic or suitable to evaluate disease development and severity, selfrated degree of ME might actually be a strong contender as the golden standard for describing disease severity.

Self-rated health and self-rated degree of CFS/ME describe the health status at the time of the survey, whereas participants assess the quality of their care from the first onset of their symptoms. This might be a problem, particularly if self-rated health and self-rated degree of CFS/ME, with its fluctuating nature, are considered individual characteristics. However, we have argued that patients most likely consider these variables as outcome measures, and the difference in observation time might thus lack significant impact. Besides, selfrated assessments of health status might not be solely limited to the current status of health or CFS/ME. ${ }^{22} 23$ The questionnaire wording may draw in this direction for self-rated health, as it emphasises health status more generally ('How would you assess your own health in general?'). However, for self-rated degree of CFS/ME, the current situation is emphasised to a greater extent ('What degree of ME do you have as of today?'). All in all, it remains unclear whether this might have affected the assessments. Most likely, it has not had any significant impact on our main results.

The cross-sectional study design implicates that no causal relationships can be established. For future research, we would recommend a longitudinal design investigating factors relevant to patients' quality assessment over time.

\section{CONCLUSIONS}

We conclude that a large proportion of women with CFS/ME rated the quality of their care as poor or very poor for primary care, specialist care and coordination of care. The dissatisfaction was higher for primary care than for specialist care, and even higher for coordination of care. Poorer self-rated health and a more severe degree of CFS/ME were associated with lower quality scores, particularly in primary care services, but were not associated with coordination between services. The findings indicate that quality in healthcare services, as assessed by patients with $\mathrm{CFS} / \mathrm{ME}$, has a significant 
potential for improvement. In order to achieve this, healthcare services must recognise and acknowledge the voice of the users, which is a fundamental value in all medical practice as well as a precondition for congruence in doctor-patient relationships and shared decision-making. This is particularly important when the consultation is likely to provide neither an explanation nor a remedy.

Acknowledgements The authors thank the members of the Norwegian ME Association for providing data for this study.

Contributors Both authors contributed to the design and conduct of the study. OSL designed the questionnaire, provided funding and collected the data. AHH undertook the statistical analyses and drafted the manuscript. OSL contributed to major improvements and critical revisions. Both authors approved the final version for publication.

Funding The Research Council of Norway, Research Program of Health and Care Sciences (Grant Number 212978/H10), funded this research.

Competing interests None declared.

Ethics approval Norwegian Data Protection Official (id. 31784).

Provenance and peer review Not commissioned; externally peer reviewed.

Data sharing statement No additional data are available.

Open Access This is an Open Access article distributed in accordance with the Creative Commons Attribution Non Commercial (CC BY-NC 4.0) license, which permits others to distribute, remix, adapt, build upon this work noncommercially, and license their derivative works on different terms, provided the original work is properly cited and the use is non-commercial. See: http:// creativecommons.org/licenses/by-nc/4.0/

\section{REFERENCES}

1. Fluge $\mathrm{O}$, Bruland $\mathrm{O}$, Risa $\mathrm{K}$, et al. Benefit from B-lymphocyte depletion using the anti-CD20 antibody rituximab in chronic fatigue syndrome. A double-blind and placebo-controlled study. PLOS ONE 2011;6:e26358

2. Bakken IJ, Tveito K, Gunnes N, et al. Two age peaks in the incidence of chronic fatigue syndrome/myalgic encephalomyelitis: a population-based registry study from Norway 2008 inverted question mark2012. BMC Med 2014;12:167

3. Capelli E, Zola R, Lorusso L, et al. Chronic fatigue syndrome/ myalgic encephalomyelitis: an update. Int J Immunopathol Pharmacol 2010;23:981-9.

4. Prins JB, van der Meer JW, Bleijenberg G. Chronic fatigue syndrome. Lancet 2006;367:346-55.

5. Brurberg KG, Fonhus MS, Larun L, et al. Case definitions for chronic fatigue syndrome/myalgic encephalomyelitis (CFS/ME): a systematic review. BMJ Open 2014;4:e003973.

6. Fukuda K, Straus SE, Hickie I, et al. The chronic fatigue syndrome: a comprehensive approach to its definition and study. International Chronic Fatigue Syndrome Study Group. Ann Intern Med 1994;121:953-9.

7. Hairon N. NICE guidance on managing chronic fatigue syndrome/ ME. Nurs Times 2007;103:21-2.

8. The Norwegian Directorate of Health. Social and health services to patients with chronic fatigue syndrome/myalgic encephalomyelitis (CFS/ME); Report no 9/2006, 2007 (in Norwegian).

9. Lian OS, Nettleton S. "United We Stand": Framing Myalgic Encephalomyelitis in a Virtual Symbolic Community. Qual Health Res 2015;25:1383-94.

10. Horton SM, Poland F, Kale S, et al. Chronic fatigue syndrome/ myalgic encephalomyelitis (CFS/ME) in adults: a qualitative study of perspectives from professional practice. BMC Fam Pract 2010;11:89.

11. Statistics about the GPs. [http://www.helsedirektoratet.no/ finansiering/refusjonsordninger/tall-og-analyser/fastlege/Sider/ statistikk-om-fastlegene.aspx] (in Norwegian).

12. Hansen $A H$, Halvorsen PA, Aaraas IJ, et al. Continuity of GP care is related to reduced specialist healthcare use: a cross-sectional survey. Br J Gen Pract 2013;63:482-9.
13. GP still on top. [http://www.forskning.no/artikler/2012/juni/323777] (in Norwegian).

14. Holmboe $\mathrm{O}$, Iversen $\mathrm{HH}$, Sjetne IS, et al. Rapport fra Kunnskapssenteret nr 18-2011. ISBN 978-82-8121-448-4 ISSN 1890-1298; 2011 (in Norwegian). http://www.kunnskapssenteret.no/ publikasjoner/commonwealth-fund-undersokelsen-i-2011-blantutvalgte-pasientgrupper-resultater-fra-en-komparativ-undersokelse-i11-land

15. Sjetne IS, Skudal KE, Haugum M, et al. Rapport fra Kunnskapssenteret $\mathrm{nr}$ 21-2014. ISBN 978-82-8121-908-3 ISSN 1890-1298; 2014 (in Norwegian). http://www.kunnskapssenteret.no/ publikasjoner/commonwealth-funds-undersokelse-i-2014-blantpersoner-i-aldersgruppe-55-ar-eller-eldre-resultater-fra-norge-og-tiandre-land

16. Shirley ED, Sanders JO. Patient satisfaction: implications and predictors of success. J Bone Joint Surg Am 2013;95:e69.

17. Lyu $\mathrm{H}$, Wick EC, Housman $\mathrm{M}$, et al. Patient satisfaction as a possible indicator of quality surgical care. JAMA Surg 2013;148:362-7.

18. Trentman TL, Chang $\mathrm{YH}$, Chien JJ, et al. Attributes associated with patient perceived outcome in an academic chronic pain clinic. Pain Pract 2014;14:217-22.

19. Poot AJ, den Elzen WP, Blom JW, et al. Level of satisfaction of olde persons with their general practitioner and practice: role of complexity of health problems. PLOS ONE 2014;9:e94326.

20. Hekkert KD, Cihangir S, Kleefstra SM, et al. Patient satisfaction revisited: a multilevel approach. Soc Sci Med 2009;69:68-75.

21. Doyle C, Lennox L, Bell D. A systematic review of evidence on the links between patient experience and clinical safety and effectiveness. BMJ Open 2013;3:pii: e001570.

22. Kaplan $\mathrm{G}$, Baron-Epel $\mathrm{O}$. What lies behind the subjective evaluation of health statr Soc Sci Med 2003;56:1669-76.

23. DeSalvo KB, Bloser N, Reynolds K, et al. Mortality prediction with a single general self-rated health question. A meta-analysis. J Gen Intern Med 2006;21:267-75.

24. Lian OS, Hansen AH. Factors facilitating patient satisfaction among women with medically unexplained long-term fatigue: a relational perspective. Health (London) 2015. doi:10.1177/13634593155 83158. http://hea.sagepub.com/content/early/2015/05/14/ 1363459315583158.long

25. Lian OS, Wilsgaard T. Patient satisfaction with primary health care before and after the introduction of a list patient system. Tidsskr Nor Legeforen 2004;124:655-8.

26. Babyak MA. What you see May not be what you get: a brief, nontechnical introduction to overfitting in regression-type models. Psychosom Med 2004;66:411-21.

27. Carruthers BM, van de Sande MI, et al. Myalgic encephalomyelitis: International Consensus Criteria. J Intern Med 2011;270:327-38.

28. Heje HN, Vedsted P, Sokolowski I, et al. Patient characteristics associated with differences in patients' evaluation of their general practitioner. BMC Health Serv Res 2008;8:178.

29. Grol R, Wensing M, Mainz J, et al. Patients in Europe evaluate general practice care: an international comparison. Br J Gen Pract 2000;50:882-7

30. Rahmqvist M, Bara AC. Patient characteristics and quality dimensions related to patient satisfaction. Int J Qual Health Care 2010;22:86-92.

31. Robson CM, Lian OS. "Are You Saying She's Mentally III Then?" Explaining Medically Unexplained Seizures in Clinical Encounters. Forum Qual Sozialforschung 2016;17, Art 2. http://nbn-resolving.de/ urn:nbn:de:0114-fqs160122

32. Woodward RV, Broom DH, Legge DG. Diagnosis in chronic illness: disabling or enabling-the case of chronic fatigue syndrome. J $R$ Soc Med 1995;88:325-9.

33. Bowen J, Pheby D, Charlett A, et al. Chronic Fatigue Syndrome: a survey of GPs' attitudes and knowledge. Fam Pract 2005;22:389-93.

34. Chew-Graham C, Dowrick C, Wearden A, et al. Making the diagnosis of Chronic Fatigue Syndrome/Myalgic Encephalitis in primary care: a qualitative study. BMC Fam Pract 2010;11:16.

35. Werner A, Malterud K. It is hard work behaving as a credible patient: encounters between women with chronic pain and their doctors. Soc Sci Med 2003;57:1409-19.

36. Anderson VR, Jason LA, Hlavaty LE, et al. A review and meta-synthesis of qualitative studies on myalgic encephalomyelitis/ chronic fatigue syndrome. Patient Educ Couns 2012;86:147-55.

37. Swoboda DA. Negotiating the diagnostic uncertainty of contested illnesses: physician practices and paradigms. Health (London, England: 1997) 2008;12:453-78.

38. Beasant L, Mills N, Crawley E. Adolescents and mothers value referral to a specialist service for chronic fatigue syndrome or 
myalgic encephalopathy (CFS/ME). Prim Health Care Res Dev 2014:15:134-42.

39. Collin SM, Sterne JA, Hollingworth W, et al. quity of access to specialist chronic fatigue syndrome (CFS/ME) services in England (2008-2010): a national survey and cross-sectional study. BMJ Open 2012;2:pii: e001417.

40. McDermott C, Lynch J, Leydon GM. Patients' hopes and expectations of a specialist chronic fatigue syndrome/ME service: a qualitative study. Fam Pract 2011;28:572-8.

41. Schoen C, Osborn R, How SK, et al. In chronic condition: experiences of patients with complex health care needs, in eight countries, 2008. Health Aff (Millwood) 2009;28:w1-16.
42. Norwegian Ministry of Health and Care Services. The Coordination Reform-proper Treatment-at the right Place and Time. Report No. 47 to the Storting; 2009 (in Norwegian).

43. The act of patient rights. Act 1999-07-02-63. [https://lovdata.no/ dokument/NL/lov/1999-07-02-63] (in Norwegian).

44. Gladwell PW, Pheby D, Rodriguez T, et al. Use of an online survey to explore positive and negative outcomes of rehabilitation for people with CFS/ME. Disabil Rehabil 2013;36:387-94.

45. Use of ICT in households, 2012, 2nd quarter. [http://ssb.no/ikthus] (in Norwegian).

46. Population's level of education, 1 October 2013. [http://www.ssb.no/en/ utdanning/statistikker/utniv/aar/2014-06-19] (in Norwegian). 